\title{
Forest cover monitoring of Bara district (Nepal) using remote sensing and geographic information systems
}

\begin{abstract}
C.M. Kandel ${ }^{1}$, M. Caetano ${ }^{2}$, and P. Cabral ${ }^{3}$
This study uses Landsat TM of 1989 and ETM+ of 1999 and 2005 imagery to evaluate forest cover dynamics during 1989-2005 in the Bara district of Nepal. The aim of the study was to analyse the extent and trend of forest cover dynamics, spatial pattern of forest and their driving forces. Forest cover change analysis was performed using objectoriented classification approach applying a standard nearest neighbour algorithm to classify the image in recognition. The overall classification accuracies were $85.71 \%$ and $88.23 \%$ for the year 1999 and 2005, respectively. Land cover maps were produced with seven land cover categories and were further reclassified as forest and non-forest areas to analyse the forest cover dynamics. Post-classification and time series analysis were carried out to detect the changes. Spatial metrics were computed for detecting the spatial pattern of forest. The classifications suggested that the amount of forest land had decreased by $11.56 \%$ during 1989-2005. Spatial metrics revealed that forest area has been fragmented and deforested with an annual rate of $0.72 \%$. The overall result demonstrates that forest area has experienced a significant shrinkage and mostly transferred into agricultural and bare land. Expected change for the year 2021 was projected using Markov Chain Analysis (MCA). The MCA result showed that forest area would decrease by $8.5 \%$ in the period of 2005-2021.
\end{abstract}

Key words: Forest cover dynamics, geographical information systems, landsat, remote sensing, spatial metrics

$\mathbf{S}^{2}$ tellite remote sensing is one of the viable techniques to monitor the changing pattern of forests. Satellite data from several moments in time allows the creation of land cover maps over large spatial extents and more frequent time steps than with expensive and detailed field studies (Nagendra, 2001). Because these classifications are spatially explicit, they not only provide information on percent changes in forest cover, but also allow for evaluation of the spatial location of these changes and their association with environmental and biophysical landscape parameters that could be critical associates of this change (Nagendra et al., 2004).

Nepal encompasses diverse ecological zones and occupies mentionable places in natural resources and richness of biodiversity in the world (FAO, 2000). Five major types of forest, i.e., tropical, sub-tropical, lowertemperate, upper-temperate and alpine forests are found in Nepal (Jackson, 1994). More than 75\% of all households and $90 \%$ of rural households rely on wood products for domestic purposes for their daily needs of timber, fuelwood, fodder, grasses, litter and traditional herbal medicines mainly from forests (Hobley, 1996). Nepal's forest has been declining in both quantity and quality. Several proximate causes and underlying driving forces (Geist and Lambin, 2002) are responsible for accelerating the deforestation and forest degradation. Legal and illegal conversion of forest land for agriculture and infrastructure development, unplanned and overexploitation of forest products, free access for grazing and uncontrolled forest fire are the major causes that create deficit of forest products on one hand and accelerate soil erosion, downstream sedimentation and decrease in agricultural productivity on the other hand (HMGN/DFRS, 1999; FAO, 2000). Some ecologists have predicted that forests of Nepal are at the threshold of degradation (Shah, 1998). The present case study analyses the spatial and temporal patterns of forest cover change in the Bara district during 1989_ 2005 based on a time series Landsat satellite images.

\footnotetext{
Asst. Remote Sensing Officer, Department of Forest Research and Survey, Babar Mahal, Kathmandu, Nepal, email: kandelcpd@gmail.com

2 Associate Professor at Instituto Superior de Estatística e Gestão de Informação, Universidade Nova de Lisboa and Principal Reseacher at Instituto Geográfico Português, Lisboa, Portugal, email: mario.caetano@igeo.pt

3 Associate Professor, Instituto Superior de Estatística e Gestão de Informação, Universidade Nova de Lisboa, Portugal, email: pcabral@isegi.unl.pt
} 


\section{Materials and methods}

\section{Study site}

Bara district is located in the south-central lowland Terai of Nepal which borders India on the south. The district is surrounded by Rautahat in the east, Parsa in the west, Makawanpur in the north and Bihar, India in the south (Figure 1). It is located between the latitudes $26^{\circ} 61^{\prime}$ and $27^{\circ} 02^{\prime} \mathrm{N}$ and the longitudes $84^{\circ} 51^{\prime}$ and $85^{\circ} 16^{\prime} \mathrm{E}$. It occupies $0.87 \%$ of the 14.7 million hectares area of Nepal's land surface, includes $1.8 \%$ of country's farmland, and bears $1.9 \%$ of Nepal's 24 million people with an average population of 7.5 per ha (CBS, 2001).

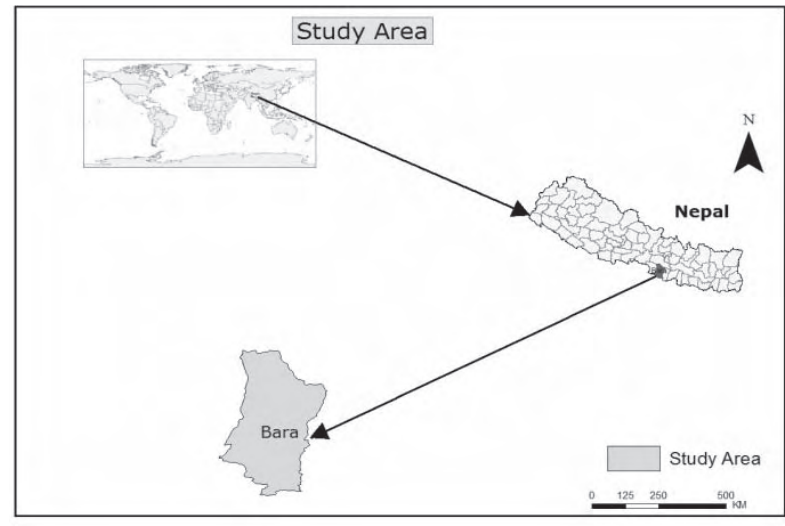

Fig 1 : Study area

This study utilizes a geographical theme obtained from the Department of Survey (DOS) of Nepal to delineate the area of the district with an area of $127,292 \mathrm{ha}$. Out of the total area, $6.3 \%$ was covered by undulated gravelly hills called the Siwalik located in the north, while the other $93.7 \%$ lies in the south Terai plain (MDM 1971), comprising 5\% of Nepal's plain land area. Most of the district's forests are located in the north, with more extensive farmland in the southern plain.

Bara district has been witnessing rapid land use and land cover dynamics following the development of roads in 1960s. The population increased from 0.25 million in 1971 (MDM, 1971), 0.41 million in 1990 (CBS, 1995), to 0.55 million in 2000 (CBS, 2001). Total population of the district is 559,137 with total households of 87,706 (CBS, 2001).

\section{Data}

Landsat TM and ETM+ satellite images acquired in 1989, 1999 and 2005 were selected for forest cover change analysis of the Bara district for the period of 1989-2005. This allowed us to provide an explicitly temporal perspective for monitoring forest cover in the Bara district. The 1989 and 1999 images were downloaded from the Global Land-Cover Facility site hosted by the University of Maryland and 2005 image (Landsat decadal, GLS-2005) was downloaded using the USGS Global Visualization Viewer. The eCognition, Idrisi Kilimanjaro, ArcGIS and FRAGSTATS softwares were used for object oriented image classification, time series change analysis/prediction, spatial data analysis and spatial metrics calculation, respectively.

\section{Methods}

Three Landsat images were processed for evaluating the forest cover dynamics in Bara district. Image classification was carried out using object-oriented classification approach applying a standard nearest neighbourhood algorithm. Forest cover change was analysed by post classification analysis, time series analysis of forest, and the spatial pattern of forest was quantified by calculating spatial metrics.

All the images downloaded were already projected into Universal Zone $45 \mathrm{~N}$ using WGS, 1984 datum. 1989 and 2005 images were georeferenced using the image-to-image registration against the 1999 image that was geo-referenced with an RMS error of 0.25 pixels. This enabled us to overlay information extracted from different satellite images within a Geographic Information Systems (GIS) to evaluate forest cover change. We realized that radiometric correction was not required for this study since there were not many radiometric distortions and also because we are doing a post-classification comparison of image derived maps.

The land cover classes applied in this study were defined according to USGS Landuse and Land Cover Classification System (USGS, 1972) and land use land cover classification systems used in Nepal. For this study, image classification was performed by emphasizing seven main land cover categories that were prevalent in the study area i.e. Upper Mixed Hardwood (UMH), Mixed Forest, Shrub, Scatter Trees (ST), Agriculture, Bare Land and Waterbodies. An object-oriented method was applied independently to the three satellite images to derive the land cover map for each date. For this study, colour was chosen as the main attribute to segment the image. Different scale parameters were explored and a scale parameter of 10 was selected based on the visual interpretation of the image segmentation 
results and the characteristics of the land cover classes existent in the study area. Seven land cover classes were created in a class hierarchy. After satisfactory segmentation, 440 training sample objects were determined using the topographic maps and Google maps to calibrate standard nearest neighbour classifier. Normalized Differential Vegetation Index (NDVI) was calculated to improve the result and assist the classification.

The accuracy assessment was carried out using 270 stratified random reference points. Random reference points were created representing all the land cover classes proportionally for each class separately in Idrisi. These points were verified with Google Earth and topographic maps (1:2500) from 1999-2001.

Although there are a wide variety of techniques, most land cover change detection analysis is performed using the simple techniques of post classification comparison (Blaschke, 2005). Post classification comparison that provide 'from-to' change information and time series analysis (Cross tab) were applied for the change analysis. CROSSTAB and Markov Chain Analysis (MCA) tools were used for change detection and prediction, respectively.

Forest cover changes can be described using information from spatial metrics. Landscape metrics are quantitative indices used to describe the structure and pattern of landscape (Herold et al., 2003). Therefore, spatial metrics were applied in this study to quantify and analyze the spatial and temporal changes of the forest land cover changes during 19892005. Six spatial metrics parameters were used for analysing the spatial pattern of forest viz. Class Area (CA), Number of Patches (NP), Edge Density (ED), Largest Patch Index (LPI), Mean Euclidian Distance Neighbour (ENN_MN), and Area Weighted Mean Patch Fractal Dimension (FRAC_AM).

\section{Results and discussion}

\section{Land cover mapping}

Land cover maps for 1989, 1999, and 2005 produced within this study area are presented in the Figure 2, 3 and 4 , respectively. Initially, the images were used to derive land cover maps with seven classes and then three maps were reclassified into binary maps: forest and non-forest. UMH, mixed forest and shrubs were merged into forest whereas agriculture, bare land, ST, and waterbodies into non-forest, respectively.

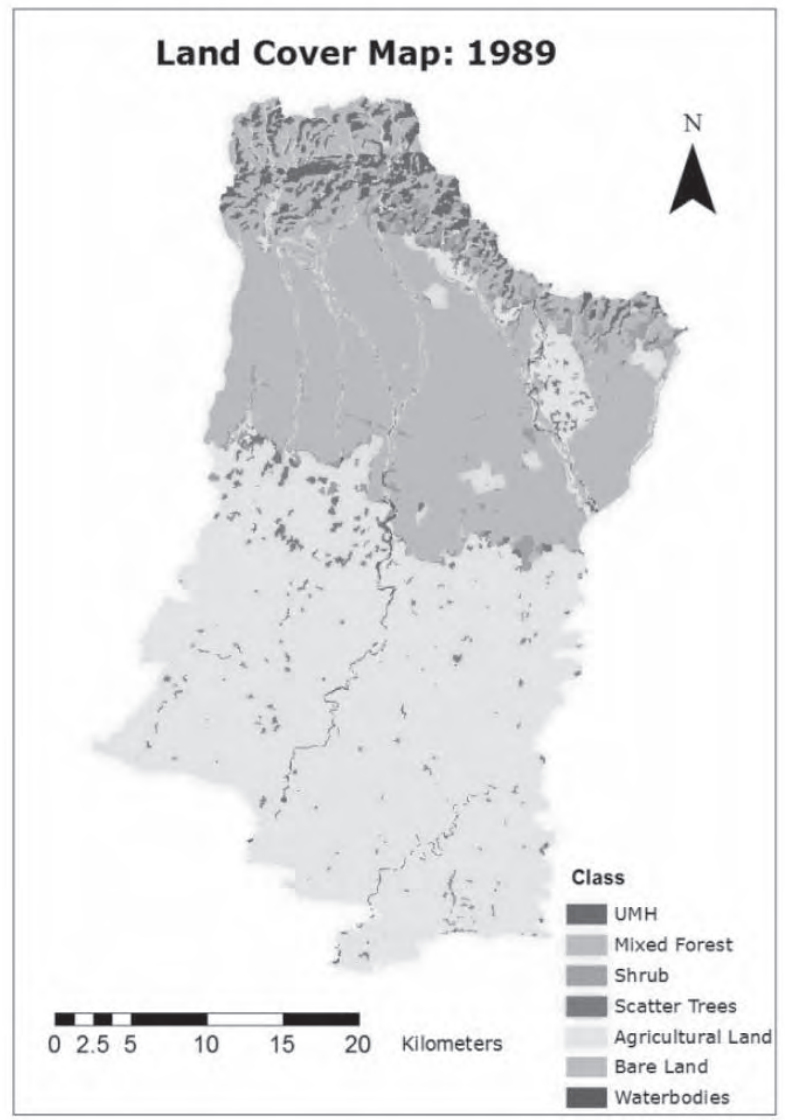

Fig 2 : 1989 land cover map

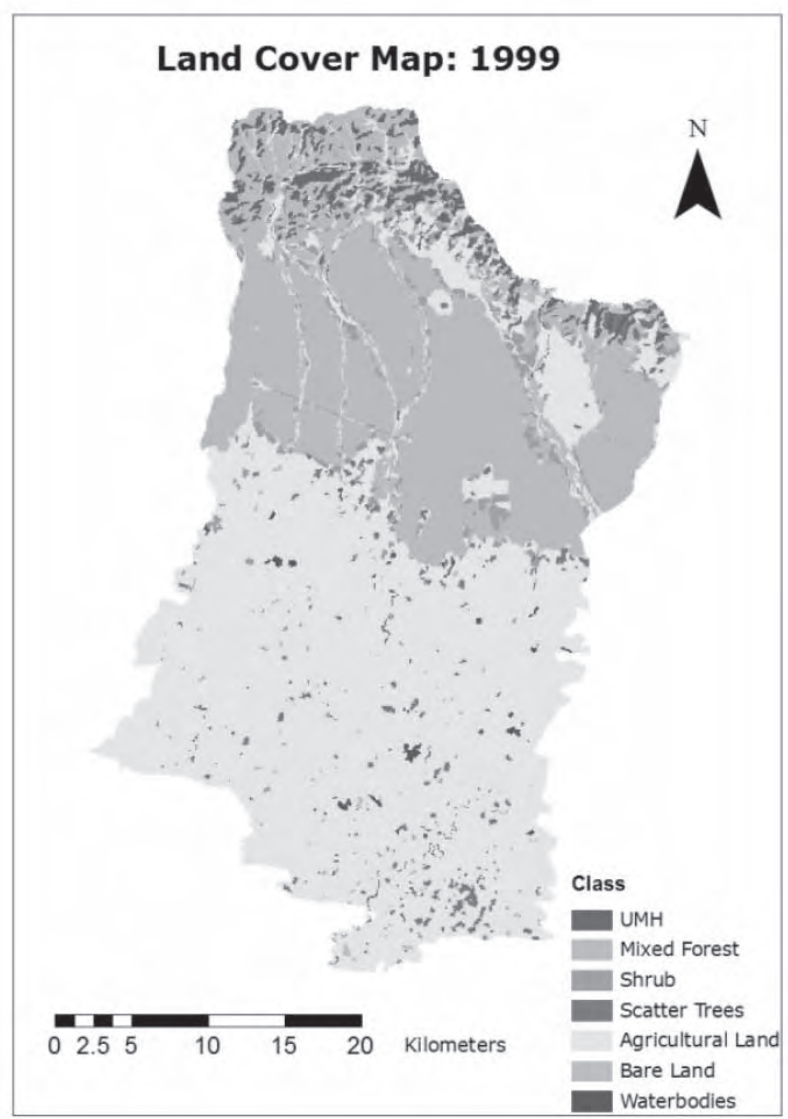

Fig 3 : 1999 land cover map 


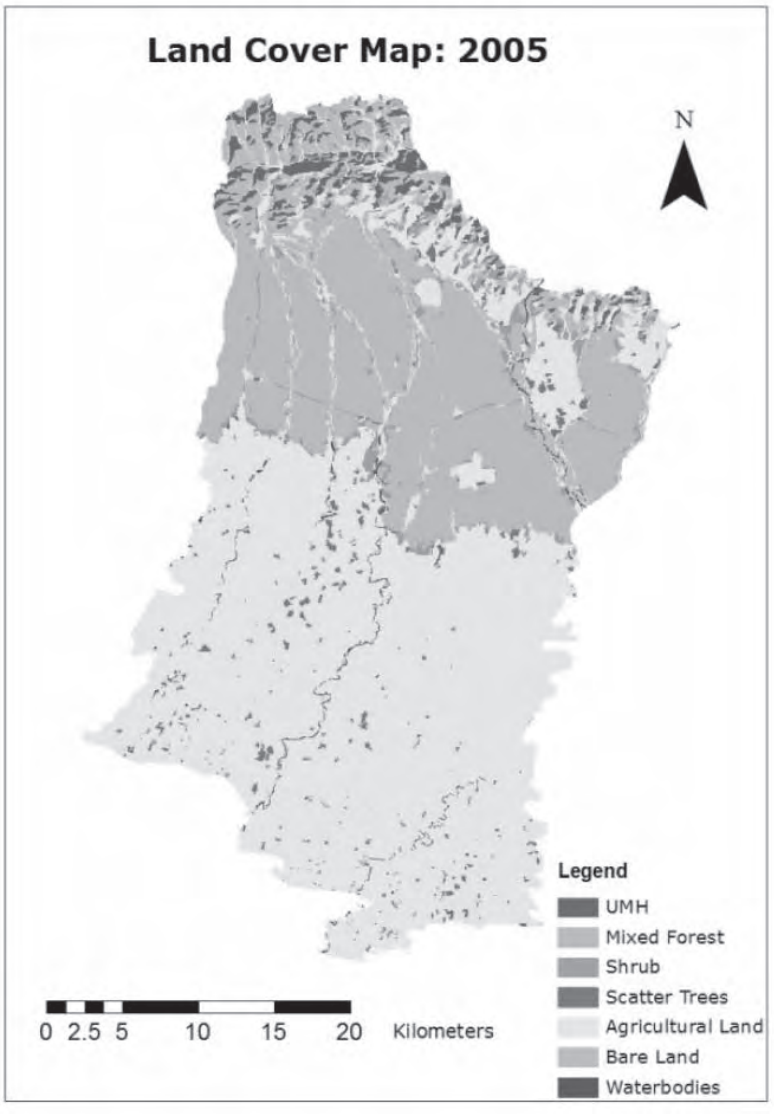

Fig 4 : 2005 land cover map

The overall accuracy and Kappa index of classification results achieved for 1999 were $85.71 \%$ and 0.72 and for $2005,88.23 \%$ and 0.76 , respectively. These results are considered as good agreement in the literature.

\section{Rate of change}

Percentual change of land during 1989-2005 is presented in Table 1. During 1989-1999, forest area had decreased rapidly with a loss of $11.49 \%$ upper mixed hardwood forest, $6.47 \%$ mixed forest, and $3.21 \%$ shrub land, respectively. Mixed forest has decreased by $5.61 \%$ followed by gradual decrease of upper mixed hardwood forest by $1.15 \%$, and shrub by $5.89 \%$, respectively during $1999-2005$. Similarly, upper mixed hardwood forest has decreased by $12.51 \%$, mixed forest by $11.72 \%$, shrub by $8.91 \%$ during 1989-2005. Forest cover including shrub has decreased by $11.56 \%$ during 1989-2005 (Table 2).

\section{Distribution of change}

Land cover dynamics from 1989 to 2005 are presented in Table 3 . The most obvious changes were the conversion of forest land (upper mixed forest, mixed forest and shrub) into cultivated land (upper mixed forest- 563 ha, mixed forest- 3392 ha and shrub- 2305 ha were converted during 1989-2005). About 425 ha of mixed forest were also transferred to bare land. A mutual land conversion is observed among upper mixed hardwood, mixed forest and shrub, for example about 1285 ha of upper mixed hardwood to mixed forest, 2354 ha of mixed forest to shrub, 1231 ha of mixed forest to upper mixed forest and 776 ha of shrub to mixed forest were transformed during 1989-2005, respectively. Some ha of forest land was transformed into other land use/cover categories but with a very low proportion of change. In both maps, there were some unclassified areas, and we present them as class- 8 in Table 3. Distribution of change is illustrated in the Figure 5 .

Table 1 : Abundance of land cover classes and land cover changes in Bara district within 1989-1999-2005

\begin{tabular}{lcccccc}
\hline Ylasses & \multirow{2}{*}{$\mathbf{1 9 8 9}(\mathbf{h a})$} & $\mathbf{1 9 9 9}(\mathbf{h a})$ & $\mathbf{2 0 0 5}$ & $\mathbf{0}$ Change (89-99) & \% Change (99-05) \% Change (89-05) \\
\hline UMH & 4095 & 3625 & 3583 & -11.49 & -1.15 & -12.51 \\
Mixed Forest & 41658 & 38963 & 36778 & -6.47 & -5.61 & -11.72 \\
Shrub & 3982 & 3854 & 3627 & -3.21 & -5.89 & -8.91 \\
ST & 1906 & 2073 & 1670 & 8.75 & -19.44 & -12.39 \\
Agriculture & 70366 & 74687 & 75705 & 6.14 & 3.36 & 7.59 \\
Bare Land & 2282 & 2077 & 2793 & -8.97 & -3.53 & -4.61 \\
Waterbodies & 845 & 836 & 806 & -1.12 & 22.39 \\
\hline
\end{tabular}

Table 2 : Forest cover change in Bara district within 1989-1999-2005

\begin{tabular}{|c|c|c|c|c|c|c|}
\hline $\begin{array}{c}\text { Year } \\
\text { Classes }\end{array}$ & 1989 (ha) & 1999 (ha) & 2005 (ha) & $\%$ Change (89-99) & $\%$ Change (99-05) & $\%$ Change (89-05) \\
\hline Forest & 49736 & 46442 & 43988 & -6.62 & -5.28 & -11.56 \\
\hline Non-forest & 75399 & 79673 & 80974 & 5.67 & 1.63 & 7.39 \\
\hline
\end{tabular}


Table 3 : Land cover change in Bara district within 1989-2005

\begin{tabular}{|l|r|r|r|r|r|r|r|r|r|}
\hline \multicolumn{1}{|c|}{$\mathbf{1 9 8 9 / 2 0 0 5}$} & \multicolumn{1}{c|}{$\mathbf{2}$} & \multicolumn{1}{c|}{$\mathbf{3}$} & \multicolumn{1}{c|}{$\mathbf{4}$} & \multicolumn{1}{c|}{$\mathbf{6}$} & \multicolumn{1}{c|}{$\mathbf{8}$} & \multicolumn{1}{c|}{ Total } \\
\hline 1 & 1937 & 1231 & 156 & 13 & 221 & 6 & 12 & 7 & 3583 \\
\hline 2 & 1285 & 33789 & 776 & 45 & 698 & 152 & 34 & 0 & 36778 \\
\hline 3 & 194 & 2354 & 501 & 41 & 452 & 75 & 9 & 1 & 3627 \\
\hline 4 & 37 & 167 & 162 & 102 & 1181 & 9 & 10 & 2 & 1670 \\
\hline 5 & 563 & 3392 & 2305 & 1679 & 66267 & 728 & 545 & 227 & 75705 \\
\hline 6 & 40 & 425 & 54 & 10 & 927 & 1218 & 115 & 2 & 2793 \\
\hline 7 & 6 & 55 & 22 & 11 & 497 & 91 & 117 & 7 & 806 \\
\hline 8 & 34 & 245 & 6 & 5 & 123 & 3 & 2 & 1879 & 2297 \\
\hline Total & 4095 & 41658 & 3982 & 1906 & 70366 & 2282 & 845 & 2125 & 127259 \\
\hline
\end{tabular}

1-UMH, 2- Mixed forest, 3- Shrub, 4-ST, 5- Agriculture7- , 6-Bare land, Waterbodies, 8-Unclassified area.

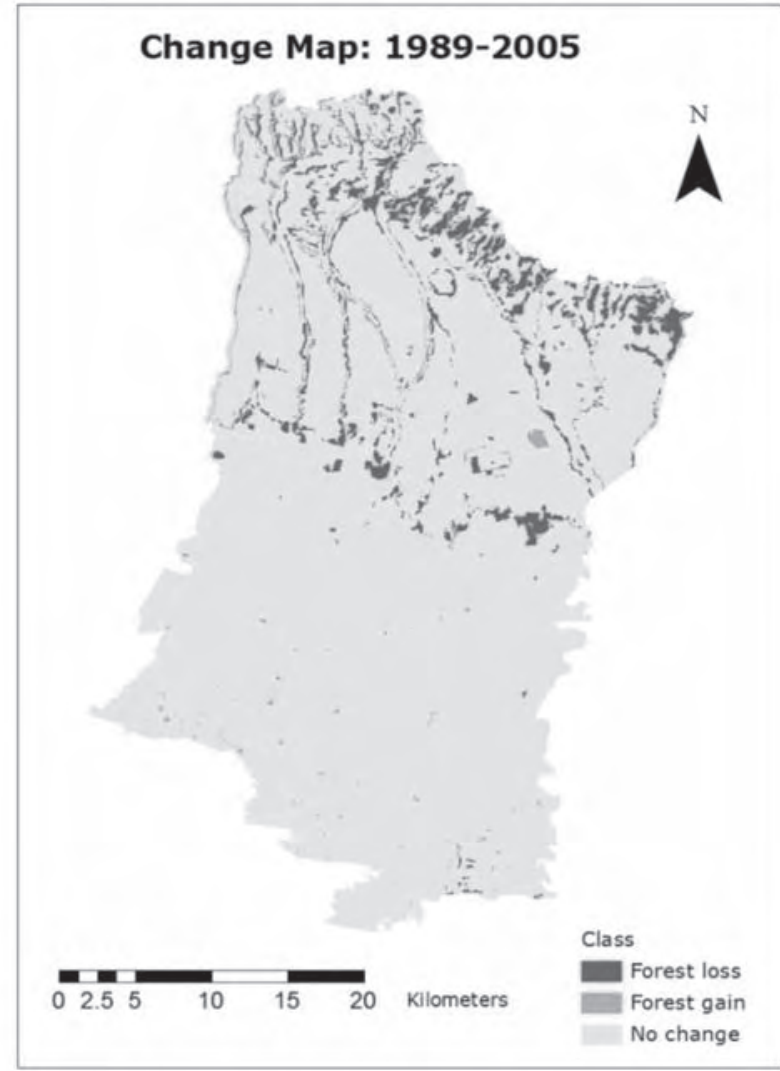

Fig 5 : Forest cover change map, 1989-2005

\section{Spatial pattern of forest}

Spatial pattern of the forest area was evaluated calculating landscape metrics in FRAGSTATS 3.3 for each individual time step. FRAGSTATS provides a very comprehensive set of spatial statistics and
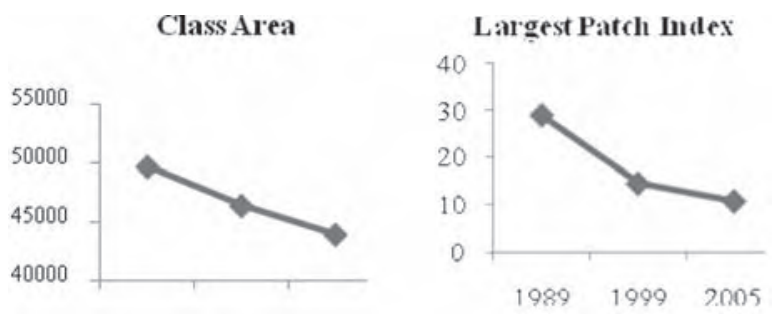
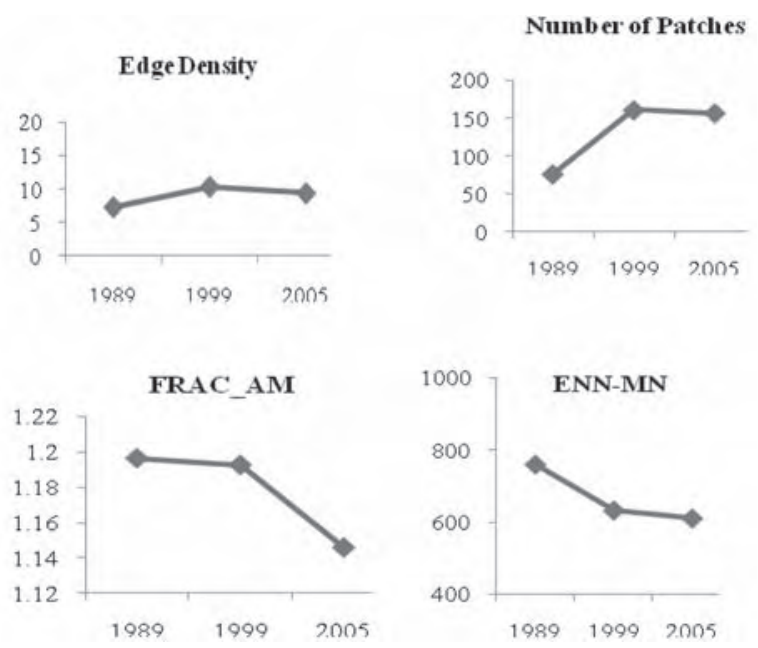

Fig 6 : Landscape structure change in Bara district (1989-2005)

descriptive pattern metrics at the patch, class, and landscape levels (Chopping and Bauer, 1996). The forest class spatial metrics and their dynamics are presented in Figure 6.

The result of the CA analysis shows that a large area of forests was converted to non-forest area during 1989-2005. NP is an excellent measure of the fragmentation of a given class within the landscape. Quite simply, the greater the number of patches, the greater the degree of fragmentation. The number of patches increased sharply during 1989-1999 and gradually during 1999-2005.

The LPI quantifies the percentage of total landscape area comprised by the largest forest patch. The LPI value of the forest area has decreased during 19892005 reflecting the isolation and fragmentation of the forest area. During 1989-1999, LPI index decreased sharply and gradually during 1999-2005. The ENN_MN also follows the same trend of LPI 
and confirms that the fragmentation of the forest has decreased during 1999-2005.

Edge Density (ED) can be defined as the length of the forest boundary divided by the total landscape. ED has increased sharply during 1989-1999, indicating the larger number of smaller patches that justifies the further fragmentation of forest area. During 1999-2005, gradual decrease of ED indicated lower rate of fragmentation. These results may be due to the conversion of smaller patches of forest into agriculture. The ENN_MN represents the average minimum distance between the individual forest areas. The ENN_MN has been reduced rapidly during 1989-1999, and slowly during 1999-2005. Decreasing trends of ENN_MN reflects that the forest patches are getting closer to each other.

The fractal dimension index is calculated by regressing the log of patch perimeter against the log of the patch area for each landscape patch. FRAC_AM value greater than 1 indicates the increase in shape complexity. Gradual decrease in the FRAC_AM and amplified later reflects that the shape of the patches is becoming simple. It may be due to conversion of forest patches into agriculture and bare land.

\section{Land use change modelling}

Based on the changes occurred during 1989-2005, changes of forest cover for the year 2021 were projected using the MCA module in Idrisi. Results of the Markovian module are presented in Figure 7. Forest area including shrub will be decreased by $8.5 \%$ during 2005-21. In terms of the ratio of the forest area to the total area of the study area, forest area will be decreased from $34.6 \%$ to $31.63 \%$ during 2005 2021.

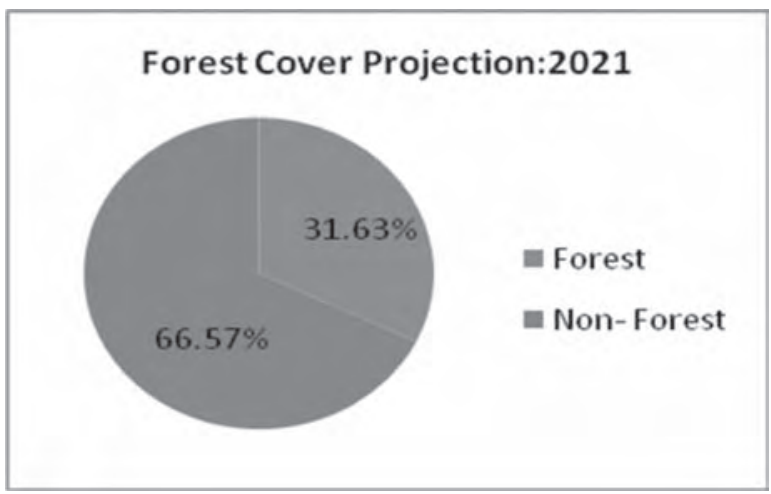

Fig 7 : Projected forest cover for 2021

Projected change was mapped using STCHOICE module in Idrisi (Figure 8). In the map, we can see that small isolated and scattered fragmented patches (Figure 9) will be cleared due to the excessive exploitation by rapidly grown population.

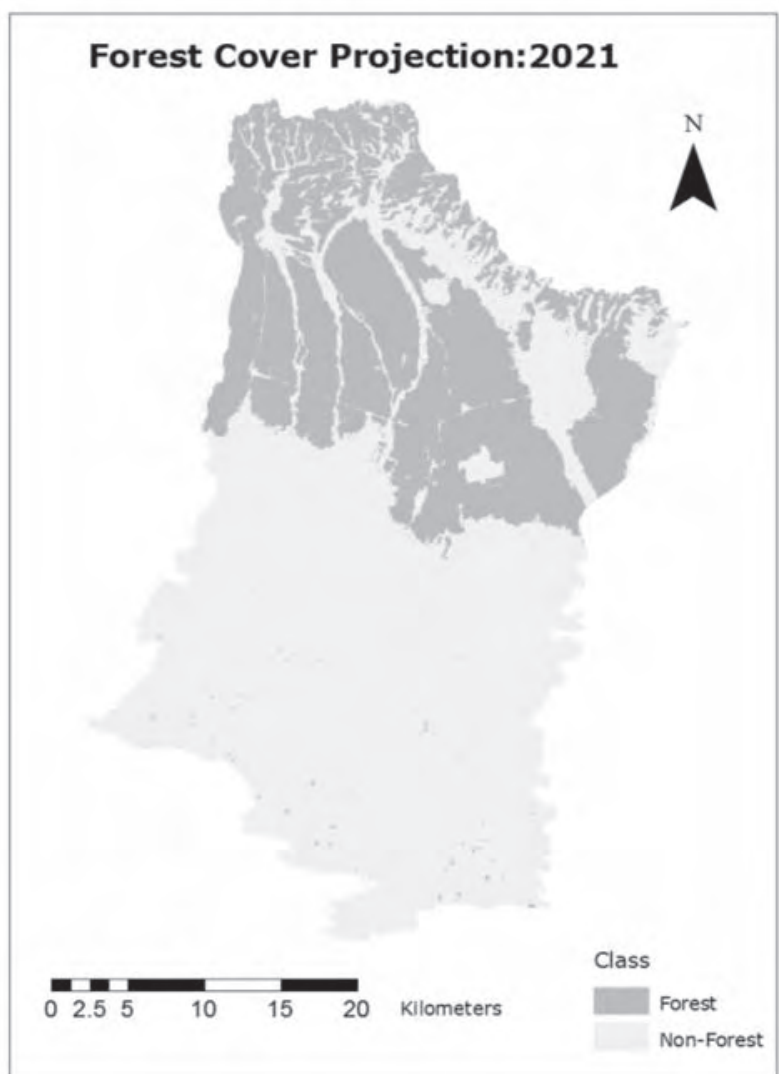

Fig 8 : Forest cover projection map for 2021

Projected Change Map: 2005-2021

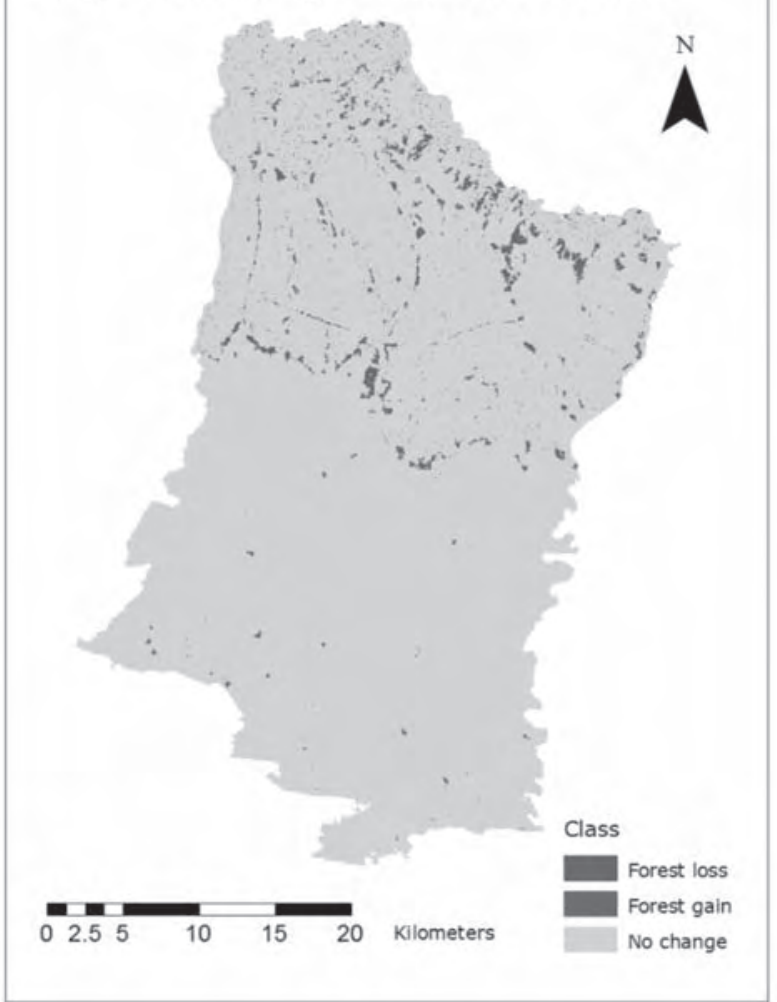

Fig 9 : Projected change map 


\section{Conclusions}

The change analysis during 1989-1999-2005 in Bara district carried out with maps derived from Landsat images revealed two important phenomena: deforestation and fragmentation of forest area. The rate of fragmentation was higher during 1989-1999 and rate of deforestation was found to be higher during 1999-2005 and the rate of deforestation was higher during 1999-2005. Rapid shrinkage of forest coverage had been experienced along highways and near settlements. This may be due to the concentration of migrants from the hill and proximity to highways (east-west and north-south). Most of the forest area has been converted into agricultural land and bare land. Annual rate of deforestation was $0.66 \%, 0.87 \%$ and $0.72 \%$ during $1989-99,1999$ 2005 and 1989-2005, respectively.

Spatial patterns of forest changed considerably during 1989-2005. From the analysis of the six spatial metrics calculated for 1989, 1999, and 2005, we can conclude that forest has been deforested and fragmented considerably. We believe that the main factors responsible for fragmentation are: agricultural sprawl, rapid population growth, expansion of road networks, increased demand of fuelwood and forage, and immigration.

If there is no change of government politics, and according to the simulations carried out within this study with MCA, it is expected that forest area will decrease by $8.5 \%$ during $2005-2021$ with a $0.53 \%$ annual rate of deforestation.

\section{Acknowledgements}

The authors would like to thank the European Commission, Erasmus Mundus Program, and MSc in Geospatial Technologies, Project no. 2007-0064, for providing financial support to conduct this study.

\section{References}

Blaschke, T. 2005. A framework for change detection based on image objects. Göttinger Geographische Abhandlungen, 113: 1-9.

CBS. 1995. Population Monograph of Nepal, HMG/N, CBS. 32, 46, 56p.

CBS. 2001. Statistical Year Book of Nepal, HMG/ N, CBS, 76-85.
Chopping P.R. and Bauer M.E. 1996. Digital change detection in forest ecosystems with remote sensing imagery, Remote Sensing Revienss, 13: 207-234.

FAO. 2000. Global Forest Resources Assessment. Food and Agricultural Organizations of the United Nations (Rome, Italy).

Geist, J.H. and Lambin, E.F. 2002. 'Proximate Causes and Underlying Driving Forces of Tropical Deforestation'.

Herold, M., Goldstein, N.C. and Clarke, K.C. 2003. The spatiotemporal form of urban growth: measurement, analysis and modeling. Remote Sensing of Environment, 86: 286-302.

DFRS. 1999. Forest Resources of Nepal (1987 1998), Department of Forest Research and Survey, Ministry of Forest and Soil Conservation, His Majesty's Government of Nepal, Forest Resource Information System Project.

Hobley, M. 1996. Participatory Forestry: The process of change in India and Nepal (Rural Development Forestry Guide 3), Overseas Development Institute (London).

Jackson, J.K. 1994. Manual of Afforestation in Nepal. Forest Research and Survey Centre, Kathmandu, Nepal.

MDM. 1971. Mechi Dekhi Mahakali (From Mechi to Mahakali), Kathmandu, Nepal.

Nagendra, H. 2001. Using remote sensing to assess biodiversity. International Journal of Remote Sensing, 22: $2377-2400$.

Nagendra, H., Munroe, D. and Southworth, J. 2004. From pattern to process: landscape fragmentation and the analysis of land use/land cover change. Agriculture, Ecosystems and Environment 101: 111115.

Shah, G. 1998. "The influence of community level institutions and their governance on use and management of natural resources in the hills of Nepal", paper presented on the Seventh Conference of International Association for the Common Property (Vancouver, Canada).

USGS. 1972. A Landuse and Land Cover Classification System for Use with Remote Senser Data, Geological Survey Professional Paper 964 (Washington, USA). 